\title{
Intensity Modulated Radiation Therapy Compared with 3D Conformal Radiotherapy for Craniospinal Irradiation in Adults - Do We Gain Anything?
}

\author{
X. Shen \\ Thomas Jefferson University and Hospitals \\ M. Studenski \\ Thomas Jefferson University and Hospitals
}

A. Harrison

Thomas Jefferson University and Hospitals

Y. Xiao

Thomas Jefferson University and Hospitals

FolHpishthis and additional works at: https://jdc.jefferson.edu/bodinejournal

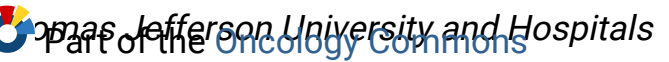

Let us know how access to this document benefits you

\section{Recommended Citation}

Shen, X.; Studenski, M.; Harrison, A.; Xiao, Y.; and Biswas, T. (2010) "Intensity Modulated Radiation

Therapy Compared with 3D Conformal Radiotherapy for Craniospinal Irradiation in Adults - Do We Gain Anything?," Bodine Journal: Vol. 3 : Iss. 1 , Article 40.

DOI: https://doi.org/10.29046/TBJ.003.1.039

Available at: https://jdc.jefferson.edu/bodinejournal/vol3/iss1/40

This Article is brought to you for free and open access by the Jefferson Digital Commons. The Jefferson Digital Commons is a service of Thomas Jefferson University's Center for Teaching and Learning (CTL). The Commons is a showcase for Jefferson books and journals, peer-reviewed scholarly publications, unique historical collections from the University archives, and teaching tools. The Jefferson Digital Commons allows researchers and interested readers anywhere in the world to learn about and keep up to date with Jefferson scholarship. This article has been accepted for inclusion in Bodine Journal by an authorized administrator of the Jefferson Digital Commons. For more information, please contact: JeffersonDigitalCommons@jefferson.edu. 


\title{
Intensity Modulated Radiation Therapy Compared with 3D Conformal Radiotherapy for Craniospinal Irradiation in Adults - Do We Gain Anything?
}

\author{
Shen, X., Studenski, M., Harrison, A., Xiao, Y., Biswas, T. \\ Department of Radiation Oncology, Thomas Jefferson University and Hospitals, Philadelphia, PA
}

\section{Purpose}

Craniospinal irradiation (CSI) remains one of the most technically challenging planning processes in radiation oncology due to its long shape especially in adults and complex target volume. In addition, CSI is associated with significant acute and late morbidities. We undertook a dosimetric analysis to determine if intensity modulated radiation therapy (IMRT) could improve target coverage while sparing normal tissue structures compared to classic 3D conformal radiation $(3 \mathrm{D}-\mathrm{CRT})$ planning.

\section{Methods}

Ten adult patients treated with CSI at Thomas Jefferson University Hospital from 2008-2009 were identified retrospectively. We generated an IMRT plan for each patient and compared with 3DCRT plans. Nine were simulated in the prone position; one patient was supine. All plans were generated using CMS XiO software. For 3D-CRT plans, opposed lateral cranial fields with collimation and couch rotation were matched to two PA spine fields extending inferiorly up to S2-S3 depending on the location of the thecal sac. For IMRT, the cranial fields were similarly planned with opposed lateral fields, and matched to two IMRT optimized spine fields, each with 5 isocentric fields. The CTV was defined as the entire spinal canal from the foramen magnum through S2-S3 similarly based on thecal sac, and extending laterally to include the nerve roots. PTV was a $5 \mathrm{~mm}$ circumferential expansion of the CTV. Organs at risk (OARs) were contoured for each patient including parotids, esophagus, thyroid, heart, lungs, larynx, stomach, small bowel, liver and kidneys. QA of the plan used both a diode array and a simple phantom with film. Statistical comparison was performed using two sided Student's t-test.

\section{Results}

Using IMRT, the volume that received $95 \%$ of the prescribed dose was $98 \%$ compared to $95.7 \%$ for $3 \mathrm{D}$ planning $(\mathrm{p}=0.11$ ). IMRT resulted in a reduced maximum point dose to the PTV, $118 \%$ vs $148 \%$ for $3 \mathrm{D}-\mathrm{CRT}(\mathrm{p}<0.001)$ and less volume of PTV $(6.2 \%)$ that received over $107 \%$ of prescribed dose vs $59.5 \%$ for $3 \mathrm{D}$-CRT ( $<<0.001)$. IMRT resulted in significantly reduced (each $\mathrm{p}<0.05$ ) mean dose to the left kidney (35\% reduction), lungs (23\%), esophagus (36\%), liver (40\%), heart (54\%), small bowel (35\%), and thyroid (35\%). Mean dose to the right kidney, stomach and parotids were not significantly different. IMRT plans required on average $48 \%$ greater monitor units than $3 \mathrm{D}$ plans (5450 MU vs 3678 MU, p < 0.001).

\section{Conclusion}

In adult patients treated with craniospinal radiation, IMRT planning provides more homogenous target coverage while reducing dose to multiple critical organs with a trade-off of greater integral dose. 